\title{
THE SILVER COULOMETER.
}

By K. E. Guthe.

1. According to Faraday's law of electrolysis, a strict proportionality exists between the quantity of electricity passing through an electrolyte and the electrochemical reaction produced by it. The latter may therefore serve for the measurement of quantity of electricity. We call the instruments employed for this purpose "voltameters" or "coulometers."

A good many different types of coulometers have been used; for example, the gas coulometer, in which the volume of the liberated gases is measured, or the iodine and the iron coulometers, in which the electrochemical change is measured by titration. The usual method, however, is the determination of the mass of a substance deposited at one of the electrodes by an electric current. ${ }^{a}$ Of the last the copper coulometer and the silver coulometer are the best-known types.

The investigations of F. and W. Kohlrausch, ${ }^{b}$ Rayleigh and Sidgwick, ${ }^{c}$ Gray, ${ }^{d}$ Schuster and Crossley, ${ }^{e}$ and Glazebrook and Skinner, ${ }^{f}$ have proved that the silver coulometer is by far the most reliable instrument of this sort and that it will give results accurate to 1 in 5,000 if certain specifications as to its construction and treatment are closely followed.

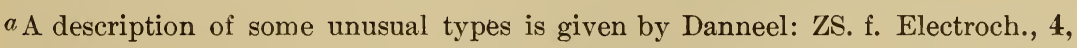
p. $154 ; 1897$.

$t$ Fr. and W. Kohlrausch: Wied. Ann., 27, p. 1; 1886.

${ }^{c}$ Rayleigh and Sidgwick: Phil. Trans., 175, p. 111; 1884.

$d$ Gray: Phil. Mag., 22, p. 389; 1886.

$e$ Schuster and Crossley: Proc. Roy. Soc., 50, p. 344; 1892.

$f$ Glazebrook and Skinner: Phil. Trans., 183, p. 567; 1892. 
2. For this reason the International Electrical Congress, held at Chicago in 1893, adopted the silver coulometer as a standard for the measurement of electric current. Though the ampere was defined as one-tenth of the unit of current of the c. g. s. system of electromagnetic units, it was added that it " is represented sufficiently well for practical use by the unvarying current which, when passed through a solution of nitrate of silver in water in accordance with standard specifications, deposits silver at the rate of 0.001118 gram per second." This value is called the electrochemical equivalent of silver.

Specifications, as referred to above, were prepared by the National Academy of Sciences and legalized in the United States in 1894. They are practically in conformity with the earlier specifications of the British Board of Trade and read as follows:

In employing the silver voltameter to measure currents of about one ampère the following arrangements shall be adopted:

The cathode on which the silver is to be deposited shall take the form of a platinum bowl not less than $10 \mathrm{~cm}$. in diameter and from 4 to $5 \mathrm{~cm}$. in depth.

The annde shall be a disk or plate of pure silver some $30 \mathrm{sq} . \mathrm{cm}$. in area and 2 or $3 \mathrm{~mm}$. in thickness.

This shall be supported horizontally in the liquid near the top of the solution by a silver rod riveted through its center. To prevent the disintegrated silver which is formed on the anode from falling upon the cathode, the anode shall be wrapped around with pure filter paper, secured at the back by suitable folding.

The liquid shall consist of a neutral solution of pure silver nitrate containing about 15 parts, by weight, of the nitrate to 85 parts of water.

The resistance of the voltameter changes somewhat as the current passes. To prevent these changes having too great an effect on the current, some resistance besides that of the voltameter should be inserted in the circuit. The total metallic resistance of the circuit should not be less than $10 \mathrm{ohms}$.

Method of making a measurement. -The platinum bowl is to be washed consecutively with nitric acid, distilled water, and absolute alcohol. It is then to be dried at $160^{\circ}$ C. and left to cool in a desiccator. When thoroughly cool it is to be weighed carefully.

It is to be nearly filled with the solution and connected to the rest of the circuit by being placed on a clean insulated copper support to which a binding screw is attached.

The anode is then to be immersed in the solution so as to be well covered by it and supported in that position. The connections to the rest of the circuit are then to be made.

Contact is to be made at the key, noting the time. The current is to be allowed to pass for not less than half an hour and the time of breaking contact observed.

The solution is now to be removed from the bowl and the deposit washed with distilled water and left to soak for at least six hours. It is then to be rinsed successively with distilled water and absolute alcohol and dried in a hot-air bath at a temperature of about $160^{\circ} \mathrm{C}$. After cooling in a desiccator it is to be weighed again. The gain in mass gives the silver deposited.

To find the time average of the current in amperes this mass, expressed in grams, must be divided by the number of seconds during which the current has passed and by 0.001118 . 

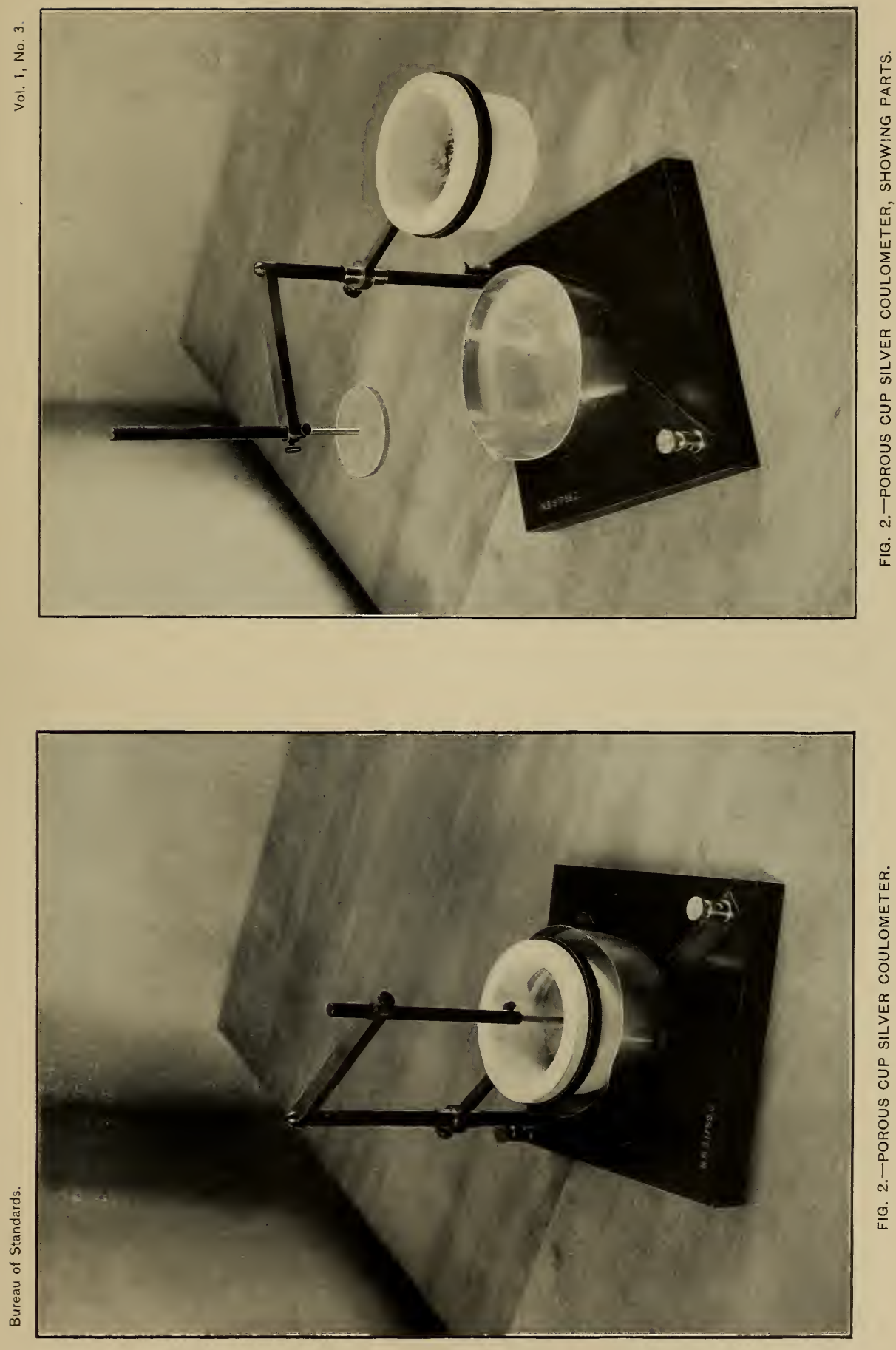
In determining the constant of an instrument by this method the current should be kept as nearly uniform as possible and the readings of the instrument observed at frequent intervals of time. These observations give a curve from which the reading corresponding to the mean current (time average of the current) can be found. The current, as calculated from the voltameter results, corresponds to this reading.

The current used in this experiment must be obtained from a battery and not from a dynamo, especially when the instrument to be calibrated is an electrodynamometer.

Other countries in which the silver coulometer has been legalized have adopted similar rules. ${ }^{a}$

3. The minute description of the form and treatment of the silver coulometer implies that a slight departure from the specifications may result in a deposit of silver not in accordance with the definition of the ampere. It was apparent that there are in the instrument disturbing factors which required a further study.

Novák, ${ }^{b}$ who worked with the Kohlrausch form-i. e., a coulometer in which a small glass bowl is suspended below the anode in order to prevent any particles from falling upon the cathode bowl-describes some of the difficulties encountered and strongly emphasizes the necessity for a thorough study of the side reactions, such as the formation of the anode slime and the possible existence of a complex silver salt in the electrolyte.

Kahle ${ }^{c}$ has shown that the electrolyte becomes acid by electrolysis and that on repeated use the deposits are too large. The Reichsanstalt recommends, therefore, that not more than 3 grams of silver should be deposited from $100 \mathrm{~cm}^{3}$ of the solution.

Leduc ${ }^{d}$ hopes to overcome all trouble by employing a large silver anode, consisting of granulated silver. He keeps the anodic current density below 0.02 ampere per $\mathrm{cm}^{2}$ and recommends that the amount of silver collected at the cathode should be large, say about 30 grams.

Patterson and Guthe ${ }^{e}$ obtained concordant results by keeping the solution in contact with silver oxide. Leduc speaks in favor of this method, but Richards's results with the same type show great variations in the amount of silver deposited by the same quantity of electricity.

$a$ The Electrician, 27, p. 325; 1891. ZS. f. Instrk., 21, p. 180; 1901.

$b$ Novák: Studie o voltametru na strúbro, Proc. Roy. Bohemian Ac. Sci., Prague, 1, pp. $387-432 ; 1892$. This paper seems to have been published in the Bohemian language only, and I failed to find any reference to it in the literature on the subject. I am indebted to Mr. C. M. Jansky for a translation of it.

$c$ Kahle: ZS. f. Instrk., 18, pp. 229 and 267; 1898.

$d$ Leduc: J. de Phys., 1, p. 561; 1902.

$e$ Patterson and Guthe: Phys. Rev., 7, p. 257; 1898. 
4. The greatest advance in our knowledge of the subject is due to the excellent researches of Richards ${ }^{a}$ and his collaborators who have shown that the main difficulty lies in the formation of a heavy anode solution containing a complex silver ion, the existence of which had already been suggested by Novák and Rodger and Watson. ${ }^{b}$ The anode solution, which in the ordinary type of coulometer sinks to the bottom of the vessel, producing there a star-shaped figure, will yield on electrolysis more silver than corresponds to the normal ion. The substance formed at the anode must be a reducing agent since oxygen tends to eliminate it. The exact chemical constitution of the substance is not known.

Novák had obtained results which at first seemed to me strong proofs of the above. In his experiments in which the coulometer forms by far the greater part of the total resistance of the circuit, he observed regularly a decrease of the current with the time, pointing to an increase of the resistance of the solution. Moreover, he found the silver loss at the anode to be greater than the gain at the cathode, while the concentration of the electrolyte seemed to have decreased. The latter was determined by precipitating the silver by means of hydrochloric acid and a careful weighing of the silver chloride. The conclusion was drawn that some of the silver in the solution was in such a form that it would not be precipitated by hydrochloric acid. Novák states that Dr. Sulc actually found silver in the filtrate after such precipitation. Such a direct proof of the presence of a complex silver salt in the electrolyzed solution seemed to call for corroboration, and the author therefore repeated the experiments. Two coulometers were used, one with a platinum bowl as eathode and a silver plate as anode, the other with a platinum crucible and a silver rod as electrodes. ${ }^{c}$ The current and the potential difference at the terminals of each coulometer were read simultaneously at short intervals and the temperatures noted. At first the resistance decreased with increasing temperature, but after a while remained constant, though the temperature still rose somewhat. Apparently an effect was obtained similar to, though considerably less pronounced than, that in Novák's experiments, in which the change in the resistance amounted to as much as 4 per cent.

The following two experiments show the reason for the increase of resistance: In the one case (A) we used the bowl $10 \mathrm{~cm}$ in diameter

$a$ Richards, Collins and Heimrod: Proc. Am. Acad., 35, p. 123; 1899. Richards and Heimrod: Proc. Am. Acad., 37, p. 415; 1902.

$b$ Rodger and Watson: Phil. Trans., 186, p. 631; 1895.

$c$ The silver used was obtained from the United States Mint and is very pure. 
and covered the bottom with a large watch glass. The anode was a rod $1 \mathrm{~cm}$ thick, the lower end of which touched the glass. The depth of the solution above the glass was $1.5 \mathrm{~cm}$. In the second case (B) the crucible was used and a small glass bowl placed at the bottom under the rod which formed the anode. In both cases the concentration of the solution was 5 per cent.

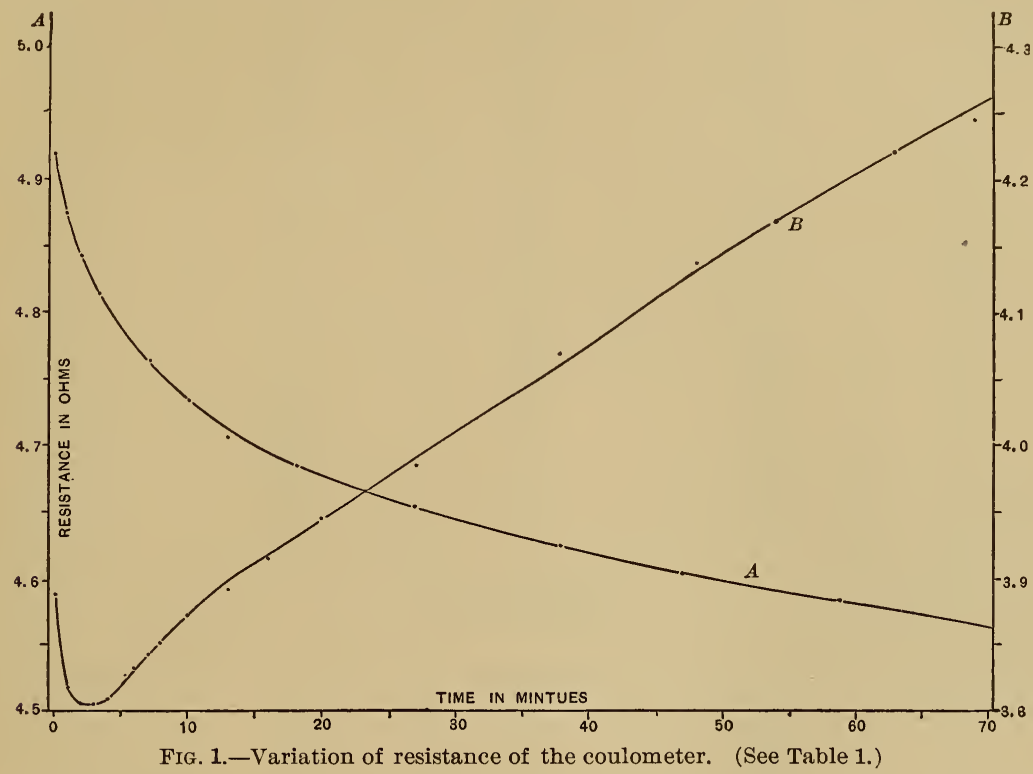

The following table shows that in the first case there is a constant decrease of resistance corresponding to the rise of the temperature. In the second the pronounced increase in the resistance can only be attributed to the collection of the heavy anode solution in the beaker, and the corresponding decrease in the concentration in the remaining electrolyte through which the current had to pass. Novák attributed the increase of the resistance partly to the formation of the anode slime and the presence of gas bubbles, but experiment (A) clearly demonstrated that this is not the case.

To test the second part of Novák's results two experiments were made with a 13 per cent solution, one with a bowl coulometer and another with a crucible as cathode. The anodes were not protected. The weighed amount of the original electrolyte was precipitated by means of pure hydrochloric acid, filtered through a Gooch crucible, and carefully weighed to $0.01 \mathrm{mg}$. After having passed a current of 1 ampere for 1.5 hours through the coulometers, the silver in the two 
Table I.

EXPERIMENT A.

\begin{tabular}{|c|c|c|c|c|}
\hline Time. & Temperature. & $\begin{array}{l}\text { Current, } \\
\text { in amperes }\end{array}$ & Pot. diff., & Resistance, \\
\hline \multicolumn{5}{|l|}{ h. $m$. } \\
\hline & 21. \& & 0.378 & 1. 860 & 4.921 \\
\hline 16 & 21.2 & .380 & 1. 854 & 4.879 \\
\hline 17 & 21.2 & .381 & 1.845 & 4. 843 \\
\hline 18 & 21.4 & .3775 & 1.820 & 4. 821 \\
\hline 20 & 21.6 & .393 & 1.885 & 4. 797 \\
\hline 22 & 21.8 & .395 & 1.882 & 4. 765 \\
\hline 25 & 22.0 & .3975 & 1. 882 & 4. 735 \\
\hline 28 & 22.2 & .3995 & 1. 880 & 4. 706 \\
\hline 33 & 22.7 & .401 & 1.880 & 4. 688 \\
\hline 42 & 23.2 & .404 & 1. 880 & 4. 654 \\
\hline 53 & 23.6 & .406 & 1. 878 & 4. 625 \\
\hline $2 \quad 02$ & 24.0 & .4075 & 1. 876 & 4. 604 \\
\hline 14 & 24.3 & 409 & 1. 874 & 4. 582 \\
\hline
\end{tabular}

EXPERIMENT B.

$\begin{array}{ll}2 & 47\end{array}$

48

49

50

51

52

53

54

55

57

300

03

07

14

18

25

35

41

50

56
22.8

23.0

23. 0

23.0

23.0

23. 05

23.1

23. 1

23. 15

23.2

23.25

23.4

23.5

23.6

23. 7

24.0

24.0

24.2

24. 2

24. 2
0. 350

.353

.353

. 3525

.352

.351

.3505

. 350

. 3495

. 348

.347

.3455

.344

.341

. 340

.3365

.333

. 331

. 3275

. 326
1. 36

1. 346

1. 341

1. 341

1. 341

1. 342

1. 343

1. 344

1. 346

1. 348

1. 350

1. 352

1. 356

1. 359

1. 361

1. 37

1. 378

1. 38

1. 383

1. 385
3. 886

3. 818

3. 803

3. 804

3. 809

3. 823

3. 831

3. 840

3. 851

3. 873

3. 890

3. 913

3. 942

3. 985

4. 003

4. 071

4. 138

4. 169

4. 223

4. 248 
solutions was again determined as before, care being taken to mix the electrolyzed solution from each vessel thoroughly before taking out the sample.

Calculation showed that in both cases the concentration had slightly increased, probably owing to the evaporation of the liquid during electrolysis. The remaining electrolyte in each instrument was then treated with hydrochloric acid, filtered, and the filtrate evaporated to dryness in a porcelain dish. There was a slight residue of a lightgreenish color, which, when heated, disintegrated and became black. It was then dissolved in nitric acid, but in the solution no silver chloride was formed on the addition of hydrochloric acid. A surplus of ammonia colored the solution slightly blue, showing that some copper was present, which was probably contained in the original electrolyte.

The same test was applied to the heavy anode solution which had collected in the beaker during the experiment (B), but in this case also no silver that had escaped precipitation by the hydrochloric acid was found in the filtrate.

5. The main problem is either to prevent the formation of complex ions or to hinder the anode solution from reaching the cathode. Attempts in the first direction by adding an oxidizing agent, for example, hydrogen peroxide, to the solution, have been unsuccessful so far, while the second problem has to a certain extent been solved. Richards places the silver rod, which forms the anode, in a fine-grained porous cup and removes from time to time the solution collecting at the bottom.

The author fully corroborated Richards's results, but proposed a different form of the anode. The bottom of a wide porous cup is filled with granulated silver, and upon this a large silver plate is pressed. In this type the rather inconvenient frequent removal of the solution was found to be unnecessary. The heavy solution is prevented by the porous cup from rapid diffusion and breaks up to a large extent when it remains in contact with silver (see figs. 1 and 2). This secondary reaction, he believes, gives rise to the formation of the wellknown dark anode slime, which is pure silver when the anode is pure.

Formerly this was thought to be peroxide of silver. Novák believes he has found two distinct modifications, according to the current density employed. Investigations at the Reichsanstalt have shown, however, that if pure silver is used at the anode no peroxide is formed. The black powder at the anode is, in the main, silver in a form similar to platinum black. It is, however, not impossible that some oxygen may be present.

The phenomenon reminds us of the appearance of finely divided 
copper on a copper anode, in a copper sulphate solution. As Fischer ${ }^{a}$ has shown, the copper goes into solution partly as cuprous ions, the amount sometimes reaching 50 per cent of the total anodic copper loss. On reaching the cooler body of the electrolyte, the cuprous sulphate breaks up into cupric sulphate and pure copper; similarly the silver may go into solution as an ion, in a lower state of oxidation, and be broken up again in the immediate neighborhood of the anode. While the usual anodes were very soon covered with anode slime after the current of one ampere was started through the coulometer, silver, freshly deposited on the rods and left in the solution, did not show the tendency to blacken, and this suggests a decrease in the secondary chemical reaction. Possibly this is due simply to the increase in the size of the electrode. Experiments with anodes of electrolytic silver will be made.

Other arrangements may be adopted to prevent the anode solution from reaching the cathode. The latter may, for instance, be suspended above the anode, or the cathode may be in form of a plate suspended in a glass vessel as Gray has done, or the two electrodes be placed in different vessels connected by a siphon. From a practical point of view the latter types are, however, less convenient than the two described above. Moreover Van Dijk ${ }^{a}$ has lately shown that when a siphon is employed the deposit is still a little larger than in the porous cup coulometer.

6. Preliminary experiments have shown that Bancroft's proposition, ${ }^{b}$ that rotating electrodes be used, promises good results. A constant stirring of the solution in the neighborhood of the anode reduces the formation of the anode slime, or, as I believe, decreases the number of ions of lower oxidation than the normal. Thus, three methods, either separately or combined, will be tried in our future work on the subject: $(a)$ addition of oxidizing agent to the solution; $(b)$ electrolyzed silver as anode; $(c)$ rotating electrodes. It is hoped that some means may be found to avoid the porous cup altogether, or at least allow the use of cups of loose texture. Another source of trouble may arise from the contact of the solution with filter paper. The organic substances contained in the latter may act chemically upon neutral silver nitrate solution. Filter paper should therefore not be used in the preparation of the electrolyte nor in the coulometer.

7. The following table shows a comparison between different types. In the first column the description of the instrument is given, and in

$a$ Fischer: ZS. anorg. Chem., 48, p. 177; 1904.

${ }^{b}$ Van Dijk: Arch. neerl. Sci. exactes et nat., 9, p. 442; 1904.

${ }^{c}$ Trans. Intern. Electr. Congr., St. Louis, 2, p. 106; 1905. 
the following column the differences between the mass of the deposit and that in the porous cup coulometer, if in the latter one gram of silver were deposited. The filter paper type includes the one used by Van Dijk and Kunst, ${ }^{a}$ who surrounded the anode by a thimble of filter paper, as used in Soxhlet's extraction apparatus. On the average the filter paper coulometer yields 1.00045 grams to one gram in the standard or porous cup type. Kahle compared the siphon type and the silver oxide type with the ordinary form. In order to include his results in this table, the average difference between the filter paper coulometer and the standard have been added to the numerical values found by him.

TABLE II.

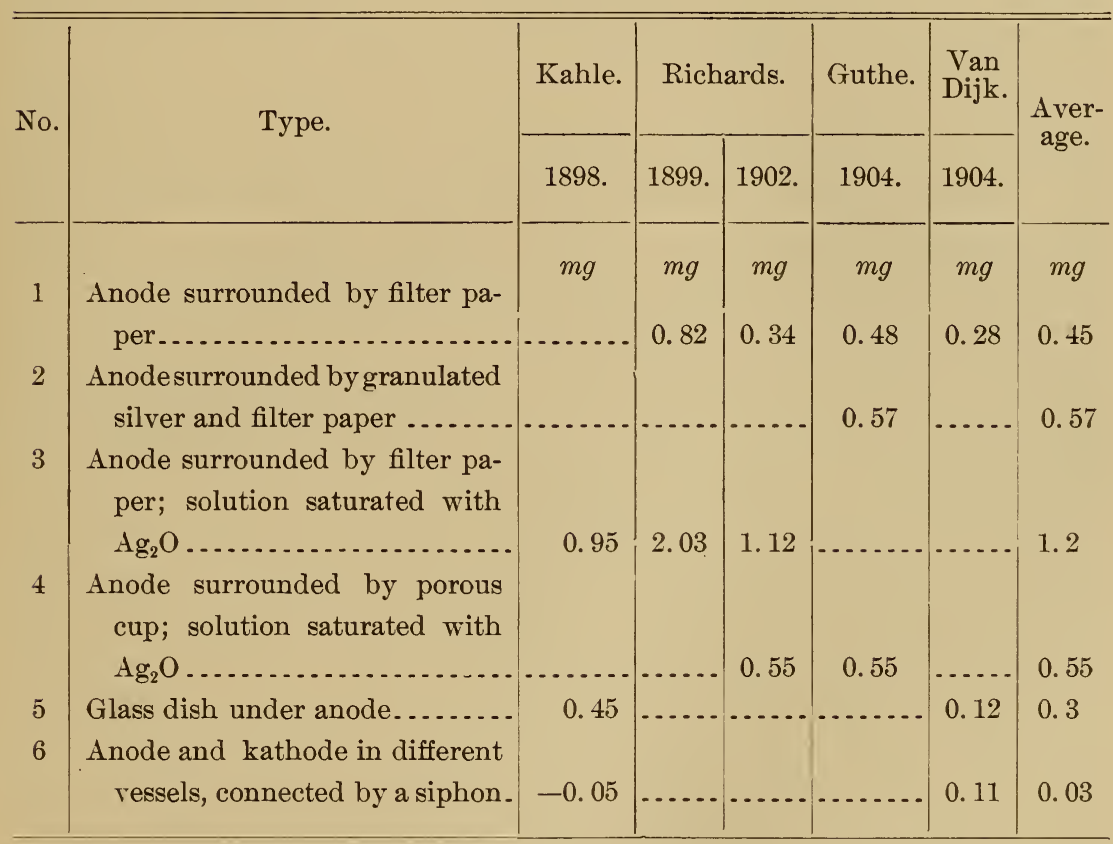

We see that the usual filter-paper type (No. 1 in the above table) with a silver nitrate solution gives a deposit 1 part in 2,000 larger than the standard porous cup coulometer. It should, however, be remarked that the porous cup does not entirely prevent the diffusion of the complex ion into the kathode space, and this will become the more apparent the longer the time of electrolysis. It would therefore be a decided advantage if a method could be devised in which the use of

$a$ Van Dijk and Kunst: Proc. Roy. Ac. Amsterdam, Jan. 21, 1904, and Ann. Phys., 14, p. 569; 1904. 
a porous cup is unnecessary. The low values obtained by Van Dijk may possibly be due to a looser texture of the cups, but it is difficult to decide this question on account of the unreliability shown by two ordinary coulometers put in series and treated in exactly the same way. Kohlrausch's form gives intermediate results, as was to be expected.

As the investigations referred to show, we can rely upon the porous cup coulometer to at least within 1 part in 10,000 , even for independent series of experiments. It would therefore be a decided step in advance if one of these types was substituted for the one now in common use. This would necessitate a change in the accepted value of the electrochemical equivalent of silver, as will be shown lateri. e., if in the future the unit of electric current should still be defined on the basis of the c. g. s. system.

8. Whether or not there are other disturbing factors of minor importance only an extended research with the porous cup coulometer will show. Some of the earlier experiments are not conclusive in this respect; they were made with the usual type, and often the differences observed amount to less than what we may expect. Besides, different investigators frequently contradict each other.

In the silver coulometer a neutral solution of silver nitrate is recommended. To test the neutrality it seems best to precipitate the silver by means of neutral sodium chloride solution and test the filtrate with methylorange. If the crystals contain acid it may be well to melt them in a silver or platinum crucible.

As Kahle has shown, a neutral solution becomes acid on being used. Richards explains this by a deionization of hydroxyl ions with the formation of silver oxide, and a consequent excess of ionized hydrogen in solution. That the mere presence of acid can not be held responsible for the trouble follows from Rodger's and Watson's and Leduc's investigations with an originally acid solution. The latter found the deposits 1 part in 5,000 lighter than without the addition of the acid to the electrolyte. In fact, if the original amount of free acid surpasses a definite percentage, then on electrolysis the amount decreases. I believe that the addition of acid or some other oxidizing agent to the anode side of a porous cup coulometer will be of help in either preventing the formation of the complex ion or in breaking it up. Experiments in this direction are in progress.

The Reichsanstalt recommends that acid be not used, lest impurities of the anode pass into solution. The influence of impurities in the solution seems, however, to be of little importance, as shown by Rayleigh and Mrs. Sidgwick, who added a large proportion of copper 
sulphate to the solution, and by Leduc, who added copper sulphate and also potassium nitrate. The deposits did not contain any of these impurities. If the current is not too large, it may be stated as a general rule that metals which require a higher cathodic difference of potential than silver will not be found in the deposits. The presence of a small amount of nitrite does not influence the result, but in a silver-nitrate solution saturated with nitrite the deposit becomes too heavy.

The presence of rarer metals would seem to be more serious, but they are hardly ever found in appreciable quantities in commercial silver, and, moreover, their electrochemical equivalents are not very different from that of silver. Extreme care in the selection of material for the electrolyte as well as the anode seems, therefore, to be unnecessary. We may even use a soluble electrode of a metal like zinc and still obtain satisfactory results, as Richards and Heimrod proved.

9. One great objection is found in the tendency to looseness which the silver obtained from nitrate solution frequently shows. The addition of a small proportion of silver acetate greatly improves the texture of the deposit, but, as was shown by Rayleigh and Mrs. Sidgwick, the deposit is always too heavy, possibly owing to an inclusion of liquid.

Richards suggests that in this case the concentration of the oxidecomplex is larger than in the nitrate solution, and therefore the deposit heavier. Lord Rayleigh employed silver chlorate as electrolyte and obtained results closely agreeing with those given by a silver nitrate coulometer. Deposits from cyanide solution are pure white and show no tendency to looseness. Leduc ${ }^{a}$ has made some experiments with potassium silver cyanide, but the amount of silver collected was entirely too small, which he attributed to a simultaneous development of hydrogen and silver at the kathode and to an occlusion of the former in the silver. Farup, ${ }^{b}$ however, has shown that hydrogen is not produced, but that the silver is dissolved by potassium cyanide if air is present in the solution. He employs, therefore, a silver coulometer with potassium silver cyanide as electrolyte, but saturates the solution with hydrogen. The results obtained by him are quite satisfactory, though I believe that with larger deposits trouble may arise due to occlusion of the liquid in the deposits. For small currents, however, this form seems to be very useful.

It is claimed that deposits from pure silver nitrate solution keep some of the liquid included. This will show itself in a decrease of

$a$ Leduc: Rapports Congr. Internat. de Phys., 1900, 2, p. 440.

b Farup: ZS. f. Electroch., 8, p. 569; 1902 . 
weight when the deposit is heated to nearly red heat, the nitrate being decomposed. According to Rayleigh and Mrs. Sidgwick, there was sometimes no loss on heating, but perhaps more often a slight decrease. Kahle advises a treatment for ten to twenty minutes with water at a temperature of $70^{\circ}$ to $90^{\circ} \mathrm{C}$., to insure the complete removal of the mother liquid. Richards also found a slight amount included; but Gray claims that with proper washing the plates may be heated without any sensible loss of weight. This statement has been recently corroborated by Van Dijk, ${ }^{a}$ who, after washing and drying at $150^{\circ}$, heated the deposits in an electric furnace to $500^{\circ}$ and $600^{\circ} \mathrm{C}$. without noticing a loss in weight. The silver may either be freshly formed on a platinum surface or on another former silver deposit. Only in the case that a new deposit is formed on an old one which had been heated to $500^{\circ} \mathrm{C}$. a decrease could be noticed, but this is explained by the cracking of the old crystals, due to the heating and consequent inclusion of liquid in the fissures. It seems, therefore, unnecessary to correct for included mother liquid in a deposit properly washed and dried.

10. The question of the solubility of silver in different liquids is one of great importance.

According to Richards and Heimrod, pure silver when boiled with a silver-nitrate solution will produce nitrite of silver in small quantities, but the Reichsanstalt makes the statement that this is not the case, and that therefore, under normal conditions, a reduction to nitrite can not be observed in a silver coulometer. Kahle, Myers, and Merrill ${ }^{b}$ observed a decrease of the weight of silver when it was treated with warm water, but Richards, Collins and Heimrod, Leduc, and Guthe could not detect any change when the deposit was left standing under water for hours, while Van Dijk asserts that in water of $80^{\circ} \mathrm{C}$. not more than $0.1 \mathrm{mg}$ is dissolved in several hours for each gram of silver deposited.

The concentration of the silver nitrate solution seems to affect only the texture of the deposit, which has a tendency to looseness if the solution is too weak in relation to the current. Though Gray considers it a mistake to use solutions containing more or even as much as 10 per cent of silver nitrate, all other observers deny any influence of concentration, and generally recommend high concentration, i. e., from 15 per cent to 30 per cent.

The Reichsanstalt has found that silver oxide is almost insoluble in concentrated nitrate solution, but the experiments referred to above show that solutions treated with the oxide are favorable to the formation of the complex ion and will yield too much silver. 
11. Schuster and Crossley stated that the deposits of silver in vacuo were about 1 part in 1,000 larger than those obtained from solutions surrounded by air, and these again larger than those formed in an atmosphere of oxygen. The former result was verified by Kahle, Richards, and Myers. ${ }^{a}$ The latter also found an increase when the liquid was saturated with nitrogen, but a decrease when the dissolved gas was carbon dioxide. It is reasonable to suppose that the increased weight of the deposit is due to the removal of oxygen from the solution and not to a change in pressure. In addition, Merrill showed that an increase of pressure to 103 atmospheres has no appreciable effect.

Rayleigh and Mrs. Sidgwick observed an increase of deposit with increase of temperature; Leduc a decrease; Richards, Collins, and Heimrod obtained as well at $60^{\circ} \mathrm{C}$. as at $0^{\circ} \mathrm{C}$. a larger deposit than at $20^{\circ} \mathrm{C}$.

12. Almost all observers agree that the size of the cathode makes no difference as long as the current density is kept within about 1 ampere per 50 to $500 \mathrm{~cm}^{2}$ of cathode surface. An objection has been made to the use of the ampere as one of the fundamental electrical standards, because the ordinary size of silver coulometer allows only currents of the magnitude of one ampere to be measured. An increase in the current limit may possibly be obtained by the use of rotating cathodes, as now employed so successfully in chemical analysis. With a rotating cathode a considerably larger current can be allowed than with a stationary cathode. According to Schuster and Crossley too great a current density at the anode is accompanied by a smaller deposit; according to Leduc just the opposite is the case, while Merrill could find no measurable effect due to a variation in the size of the electrodes. The author's experiments lead to the conclusion that in the porous-cup coulometers the size of the anode does not come into account. It is, however, well to keep in mind that the drop of potential should not be large enough to allow a decomposition of water. In all ordinary forms of silver coulometers the potential difference is sufficiently small.

With the usual type of coulometer Kahle as well as Van Dijk obtained a somewhat larger deposit on a silver cathode than on platinum, and considers, therefore, as normal deposits those obtained on silver. Richards and Heimrod confirm this observation, but find that with a porous-cup coulometer no such difference appears. The author also obtained identical results when the cathode was platinum as when silver had been previously deposited on it. The explanation of Kahle's results is to be sought in the action of silver upon the heavy anode liquid mentioned above. 


\section{The Electrochemical Equivalent of Silver.}

13. The electrochemical equivalent of silver has been determined repeatedly by absolute measurements, $i$. e., by means of instruments which allow a calculation of the current in terms of the fundamental units of mass, length, and time. Among the earlier investigations only those of Rayleigh and Mrs. Sidgwick and of Fr. and W. Kohlrausch can be considered accurate. In order to express all measurements in terms of the same standard, the different values found have been reduced to those given by the porous-cup coulometer, and these are given in the last columns of the following table. Since in most cases the exact conditions of the experiments are unknown, these corrected values will simply give a general idea of the agreement between different observers.

As will be seen, Richards's and Van Dijk's corrections differ considerably. In deciding upon my own corrections I have taken the average of these two and those proposed by myself elsewhere. ${ }^{a}$

It was thought unnecessary to take into account the possible effect of included mother liquid.

From this list we see that the results obtained so far are not very satisfactory.

The most reliable experiments made in the United States, England, Germany, and the Netherlands lead to an average of $1.1178 \mathrm{mg}$ for the electrochemical equivalent of silver, while the last two French determinations give a value of about 1 in 1,000 higher than this. Redeterminations in absolute measure with the use of a reliable form of coulometer are highly desirable.

14. The electrochemical equivalent of silver may also be expressed in terms of the electromotive force of a standard cell, i. e., by comparing the electromotive force of the cell with the potential difference produced by the current at the terminals of a known resistance. The electrochemical equivalent will depend upon the value chosen for the electromotive force of the standard cell. The legalized value for the Clark cell is 1.434 volts. But this is probably too high. In Germany the electromotive force of the Clark cell is derived from silver-coulometric measurements, and the Reichsanstalt has chosen as the working value 1.4328 volts at $15^{\circ} \mathrm{C}$. In the following table the electrochemical equivalent of silver is calculated as well for an electromotive force $=1.434$ as for 1.433 volts.

$a$ Transactions of the International Electrical Congress, St. Louis, II, p. 104, 1905. 


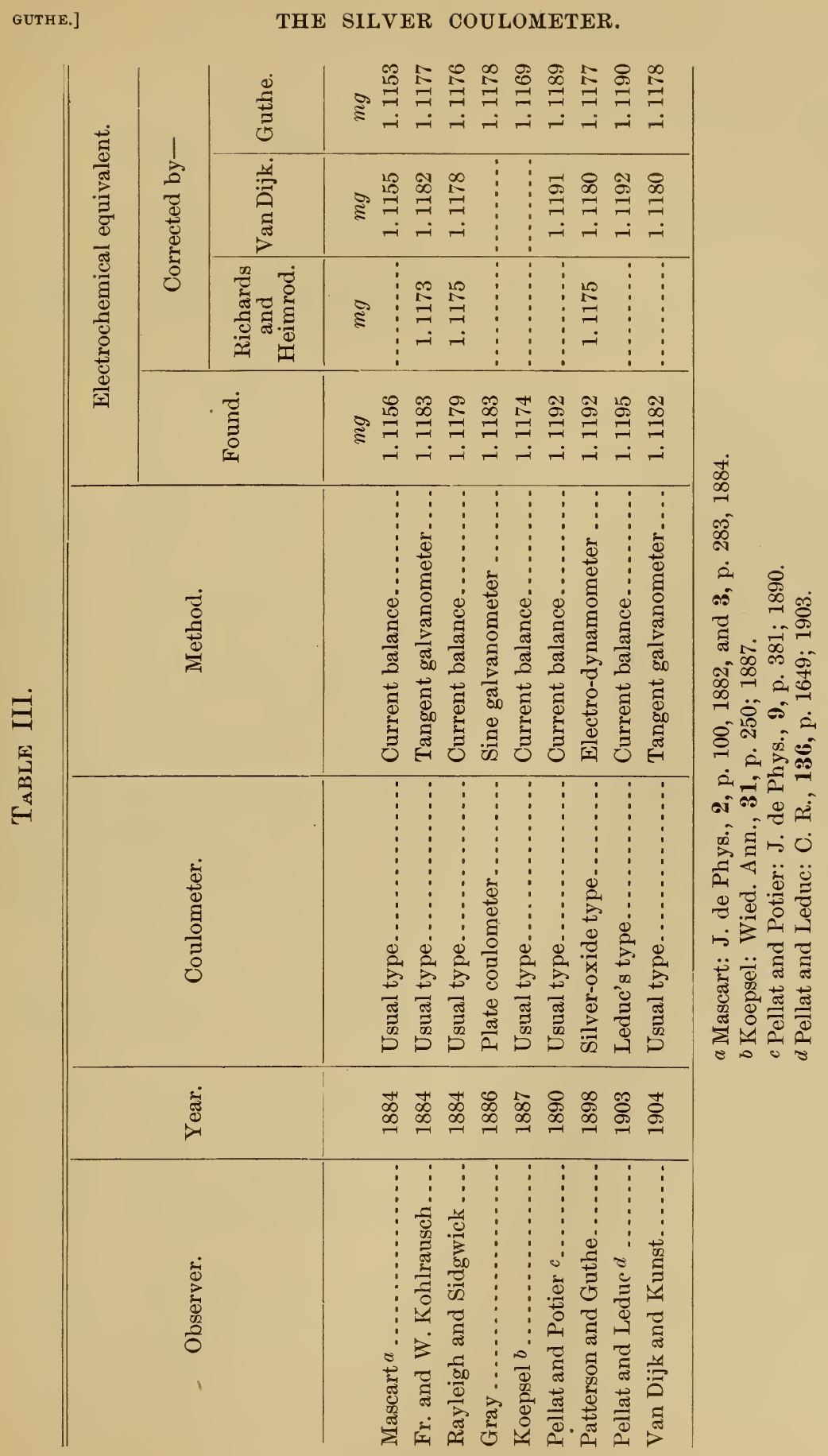

363 
TABLE IV.

\begin{tabular}{|c|c|c|c|c|c|}
\hline \multirow{3}{*}{ Observer. } & \multirow{3}{*}{ Year. } & \multicolumn{4}{|c|}{ Electrochemical equivalent. } \\
\hline & & \multicolumn{2}{|c|}{$\mathrm{E}=1.434$ volts } & \multicolumn{2}{|c|}{$\mathrm{E}=1.433$ volts } \\
\hline & & $\begin{array}{l}\text { Usual } \\
\text { type. }\end{array}$ & $\begin{array}{l}\text { Porous } \\
\text { cup C. }\end{array}$ & $\begin{array}{l}\text { Usual } \\
\text { type. }\end{array}$ & $\begin{array}{l}\text { Porous } \\
\text { cup C. }\end{array}$ \\
\hline & & $m g$ & $m g$ & $m g$ & $m g$ \\
\hline Carhart $a$ & 1882 & 1.1172 & 1.1167 & 1.1180 & 1. 1175 \\
\hline Rayleigh and Sidgwick . & 1884 & 1.1183 & 1. 1178 & 1.1192 & 1. 1187 \\
\hline Von Ettinghausen ${ }^{t} \ldots \ldots \ldots \ldots$ & 1884 & 1.1180 & 1.1175 & 1.1188 & 1.1183 \\
\hline Glazebrook and Skinner....... & 1892 & 1.1183 & 1. 1178 & 1. 1191 & 1. 1186 \\
\hline Perot and Fabry ${ }^{c}, \ldots \ldots \ldots \ldots$. & 1898 & 1.1193 & 1.1188 & 1.1120 & 1. 1196 \\
\hline Kahle..... & 1898 & 1.1173 & 1.1167 & 1.1180 & 1. 1175 \\
\hline Guthe.... & 1904 & 1.1174 & 1. 1168 & 1.1181 & 1. 1176 \\
\hline
\end{tabular}

a Carhart: Am. Jour. Sci., 28, p. 374; 1884.

3 Von Ettinghausen: ZS. f. Electrotechnik, 2, p. 484; 1884.

$c$ Perot and Fabry: Ann. Fac. des Sci. Marseille, 8, p. 201; 1898.

In the case of Perot and Fabry, who used a Clark cell at $0^{\circ} \mathrm{C}$. and found its electromotive force to be 1.4522 volts, using $1.118 \mathrm{mg}$ as the electrochemical equivalent, the difference of 0.0164 volt given by the Reichsanstalt has been used to reduce to $15^{\circ} \mathrm{C}$., instead of the ratio given by them. The latter would give $1.1180 \mathrm{mg}$ in the first column and corresponding values in the others and make the agreement with the earlier experiments a very close one.

The large differences between the earlier and the more recent comparisons can hardly be due to the silver coulometer alone. Doubtless the Clark cell comes in for its share.

Wolff and Carhart and Hulett have lately discovered an electrolytic method of preparing mercurous sulphate. Cadmium standard cells, in which this substance is used, show, according to preliminary reports, an excellent agreement among themselves, and no variation in their electromotive force in course of time as far as can be ascertained during a relatively short period.

With the improvement of our standard of electromotive force and the construction of a reliable silver coulometer, a wide and interesting field for research has been opened, and it is to be expected that the new determination of the volt and the ampere, which are in progress in the different countries, will show an agreement considerably better than the older ones. 



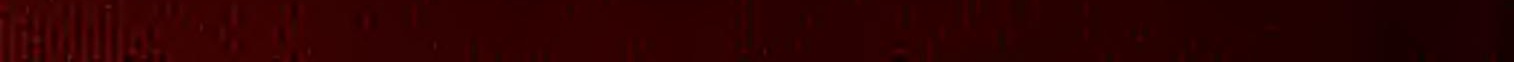

